
NEW NORMAL PADA PESERTA DIDIK MADRASAH IBTIDAIYAH

\author{
Jamilatun Nafi'ah \\ Institut Agama Islam Al-Falah As-Sunniyyah Kencong-Jember \\ Fiamila64@g.mail.com
}

\begin{abstract}
E-learning delivered by the government during the Covid 19 pandemic can indeed be applied by a number of institutions in Indonesia, but the habituality of conventional learning that spontaneity changes distance learning makes educators and students have difficulties and limitations both in facilities and materials provided by teachers. This is felt for students, especially at the elementary school level who still need intensive face-to-face guidance. Therefore, there needs to be a combination of online learning with conventional learning or through face-to-face. Therefore, to answer the problem blended learning is also applied in learning during Covid 19 until the current New Normal era. Even so, in the application of both e-learning and blended learning educators need to pay attention to matters related to facilities, and conditions of learners and understand the technical and learning steps well.
\end{abstract}

Keywords : E-Learning, Blended Learning, New Normal

\begin{abstract}
Abstrak
Pembelajaran e-learning yang sampaikan oleh pemerintah saat pandemi Covid 19 memang bisa di terapkan oleh sejumlah institusi di Indonesia, namun keterbiasaan pembelajaran konvensional yang spontanitas berganti pembelajaran jarak jauh membuat para pendidik maupun peserta didik mengalami kesulitan serta keterbatasan baik dalam fasilitas maupun materi yang di berikan guru. Hal ini dirasakan bagi peserta didik khususnya di tingkat sekolah dasar yang masih membutuhkan bimbingan secara intensif secara tatap muka. Oleh karena itu, perlu adanya kombinasi antara pembelajaran daring dengan pembelajaran secara konvensional atau melalui tatap muka. Maka, untuk menjawab permasalahan tersebut blended learning turut di terapkan dalam pembelajaran di kala Covid 19 hingga era New Normal saat ini. Meski begitu, dalam penerapannya baik e-learning maupun blended learning para pendidik perlu memperhatikan hal-hal terkait fasilitas, serta kondisi peserta didik serta memahami teknis dan langkah pembelajarannya secara baik.
\end{abstract}

Kata Kunci : E-Learning, Blended Learning, New Normal

\title{
PENDAHULUAN
}

Situasi pandemi covid 19 yang mulai terjadi di Indonesia pada tahun 2020 telah meresahkan di berbagai sektor khususnya pendidikan. Sebuah wabah yang tak kunjung usai hingga memunculkan suatu kebiasaan baru atau yang kita sebut New Normal ini telah membuat 


\section{Jamilatun Nafi'ab}

perubahan serta pembaharuan pada sistem pendidikan. Salah satu perubahan nyata yang terealisasikan pada praktiknya adalah dalam hal proses pembelajaran di sekolah. Pembelajaran yang semula dilaksanakan secara tatap muka dengan segala aktivitas belajarnya di sekolah harus tertahan secara daring (dalam jaringan) dan di anjurkan untuk tetap melakukan pembelajaran dirumah masing-masing.

Pusat aktivitas bekerja maupun belajar yang beralih di rumah membuat sejumlah pakar, praktisi pendidikan termasuk guru, mau tidak mau harus melakukan terobosan dalam pembelajaran. Kementerian Pendidikan dan Kebudayaan (Kemendikud) telah memberikan instruksi pembelajaran yang di gunakan kala pandemi bisa melalui online dengan beragam elearning di dalamnya. Pemerintah pun juga telah memfasilitasi pembelajaran melalui salah satu stasiun televisi di Indonesia.

Langkah yang di anjurkan pemerintah tersebut bisa saja menjadi angin segar bagi beberapa pendidik maupun peserta didik di sebagian wilayah khususnya perkotaan. Namun, belum tentu menjadi solusi bagi para penghuni lembaga pendidikan yang berada di daerah pedesaan. Tantangan demi tantangan mulai di temukan saat anjuran pembelajaran online tersebut di jalankan. Mulai dari, kondisi keluarga peserta didik yang kurang mampu dan belum memiliki gadget (handphone) sebagai alat untuk menerima informasi materi dari guru, sulitnya akses jaringan internet di sebagian wilayah pedesaan, hingga dilema guru dalam menjalankan pembelajaran daring melalui e-learning di masa pandemi tanpa pedoman.

Selain itu, dalam penerapannya pembelajaran daring menimbulkan dampak dan dan kendala yang di rasakan oleh peserta didik, guru dan juga orang tua. Dampak yang di alami peserta didik antara lain, kurang memahami materi pembelajaran yang telah di berikan oleh gurunya. Pembelajaran melalui e-learning juga akan terasa membosankan apabila terlalu banyak tugas yang di berikan kepada peserta didik. Maka dari itu sebagai pendidik harus selalu berinovasi dalam merancang pembelajaran khususnya saat menggunakan pembelajaran daring melalui elearning ini. ${ }^{1}$ Usaha dalam berinovasi merancang pembelajaran merupakan salah satu perjuangan bagi pendidik dalam melakukan pembelajaran agar tujuan pembelajaran yang di berikan dapat tercapai dan sesaui dengan kompetensi yang di harapkan.

\footnotetext{
${ }^{1}$ UhlulQoriawati,Lu'luil Maknun, Jurnal Edukasi Madrasah Ibtidaiyah, Upaya Peningkatan Kualitas Pembelajaran Daring Bagi Pesrta Didik pada masa Pandemi Covid-19, Vol 3 No.1 Januari 2021, 7
} 
Ijtihad dalam merancang pembelajaran ini terkait dengan firman Alloh swt dalam QS. AlMaidah ayat 35:

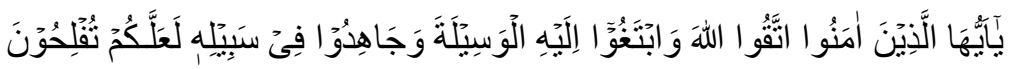

Artinya : "Wahai orang-orang yang beriman! Bertakwalah kepada Allah dan carilah wasilah (jalan) untuk mendekatkan diri kepada-Nya, dan berjihadlah (berjuanglah) di jalan-Nya, agar kamu beruntung." (QS. Al-Maidab) ${ }^{2}$

E - learning bukanlah hal asing bagi dunia pendidikan. jelas karna e-learning sebenarnya sudah mulai dipopulerkan sejak tahun 1960, ketika ditemukannya program Computer Based Training pertama (CBT program). Program ini juga dikenal dengan nama PLATO (Programmed Logic for Automated Teaching Operations). Program tersebut dibuat untuk para mahasiswa yang belajar di University of Illinois, namun akhirnya program tersebut digunakan di sekolah-sekolah hampir di seluruh daerah disana. ${ }^{3}$ E-learning di Indonesia mulai ada sejak tahun 90 -an dengan didahului oleh perkembangan teknologi informasi. Mulai tahun 2000, setelah krisis moneter di Indonesia mulai mereda banyak organisasi yang kembali merintis perkembangan e-Learning.

Banyak orang menggunakan istilah yang berbeda -beda dengan e-learning, namun pada prinsipnya e-learning adalah pembelajaran yang menggunakan jasa elektronika sebagai alat bantunya. Perkembangan e- learning yang masih relative baru, mengakibatkan definisi dan implementasi sistem e-learning sangatlah bervariasi dan belum ada standar yang baku. Apalagi bagi lembaga pendidikan yang masih minim fasilitas dan terbiasa dengan sistem pembelajaran konvensional tatap muka, pastilah memiliki tantangan dalam menerapkan pembelajaran elearning secara spontan di era pandemi covid 19.

Penerapan e-learning bisa saja berlangsung secara continue pada institusi yang sudah terbiasa dengan e-learning serta kemampuan dan kelengkapan fasilitasnya. Namun, bagi Lembaga Pendidikan yang masih terbatas fasilitas dan umumnya di daerah pedesaan, melakukan e learning secara terus menerus kurang efektif karna adanya kendala baik jaringan maupun fasilitasnya. Sehingga pada praktiknya, pembelajaran yang dilakukan kala pandemic covid-19 ini turut muncul yang namanya Blended Learning sebagai alternatifnya. Blended Learning merupakan penggabungan antara pembelajaran dengan menggunakan e-learning (elektronik Learning) dengan pembelajaran konvensional (tatap muka).

\footnotetext{
${ }^{2}$ Departemen Agama RI. Al-Qur'an dan Terjemahannya(Surabaya: CV.Pustaka Agung Harapan, 2006), 250

${ }^{3}$ HS Wibowo - Indonesian Journal of History Education, Efektivitas Pembelajaran Sejarah Dengan Mengunakan Model Pembelajaran E -Learning Vol.3 No.1 17 Oktober 2014, 4 (di akses 20 Mret 2020)

25| Jurnal Auladuna
} 


\section{Jamilatun Nafi'ab}

Berdasarkan pembahasan tersebut, penulis tertarik untuk memaparkan secara lebih lanjut terkait pembelajaran e learning dan blended learning, perkembangan sekaligus variasi pembelajaran e learning dan blended learning yang bisa di terapkan secara efisien dan tepat guna bagi peserta didik khususnya di tingkat madrasah ibtidaiyah.

\section{PEMBAHASAN}

Siapapun yang memulai kata Normal baru ini, jelas ada benang merah kesepahaman. Normal baru, secara umum di sepakati tanpa sadar, yakni menerangkan suatu kondisi yang terbentuk akibat lamanya kehidupan social masyarakat selama Covid-19. Waktu lama disini berarti cukup untuk menyamakan pendapat terkait waktu.

\section{A. Mengenal Istilah Normal Baru (New Normal)}

Beberapa ahli yang menetapkan berapa lama kebiasaan baru tercipta antara lain, Dr. Maxwell Maltz melalui bukunya Psychocybernetics menetapkan 21 hari untuk membentuk kebiasaan baru. Namun, Phillippa Lally dari University College London menyatakan bahwa ratarata 66 hari untuk merubah pembiasaan menjadi kebiasaan. Istilah new normal memang sempat menjadi perdebatan oleh sebagian msyarakat Indonesia bahkan ada yang menyebut istilah new normal lebih tepat menggunakan kata apnormal. ${ }^{4}$ Kondisi saat pandemi Covid 19 bisa saja di sebut apnormal Namun, kembali lagi pada penelitian Maxwell dan Phillippa jika pada kondisi tersebut manusia melakukan kegiatan baru selama lebih dari 100 hari maka apnormal tersebut akan tetap berubah menjadi Normal Baru.

Selain itu, Achmad Yurianto (2020), menegaskan bahwa new normal menurut Pemerintah Indonesia adalah tatanan baru untuk beradaptasi dengan Covid-19. Masyarakat harus menjaga produktivitas di tengah pandemi virus corona dengan tatanan baru atau yang disebut new normal. "Sekarang satu-satunya cara yang harus dilakukan bukan dengan menyerah tidak melakukan apapun, melainkan kita harus menjaga diri agar dalam situasi seperti ini tetap produktif namun aman dari Covid-19, sehingga diperlukan tatanan yang baru". ${ }^{5}$ Himbauan yang di nyatakan juru bicara penanganan Covid 19 tersebut secara teknis berarti kita harus menerapkan pola hidup dan kebiasaan sehat secara teknis dengan cara mencuci tangan pakai

\footnotetext{
${ }^{4}$ HS Wibowo - Indonesian Journal of History Education, Efektivitas Pembelajaran Sejarah Dengan Mengunakan Model Pembelajaran E -Learning Vol.3 No.1 17 Oktober 2014,4 (di akses 20 Maret 2020) ${ }^{5}$ HS Wibowo - Indonesian Journal of History Education, Efektivitas Pembelajaran Sejarah Dengan Mengunakan Model Pembelajaran E -Learning Vol.3 No.1 17 Oktober 2014,4 (di akses 20 Maret 2020), 4
} 
sabun, memakai masker, menjaga jarak, dan menghindari kerumunan demi kesehatan dan keselamatan bersama.

New Normal Pasca Covid 19 telah mengubah berbagai sector termasuk pendidikan. Mau tidak mau dunia pendidikan harus di hadapkan pada proses pembelajaran secara digitalisasi. Covid 19 memang telah banyak menghadirkan kerugian di berbagai bidang namun jika di lihat dari sudut pandang positifnya, adanya Covid 19 turut menggebrak dunia pendidikan dalam membangkitkan inisiatif untuk berubah dan berinovasi. Diantara perubahan yang terealisasikan pada proses pembelajaran saat pandemic covid 19 adanya penerapan pembelajaran e learning.

\section{B. Pengertian E-Learning dan Blended Learning}

Pembelajaran e learning mungkin masih jarang di terapkan pada lembaga sekolah karna dalam penerapannya di perlukan beberapa fasilitas yang mendukung teknis pembelajaran tersebut. Namun, mengapa pada saat pandemi Covid 19 e learning bisa di terapkan secara menyeluruh? Lalu, bagaimana penerapan e learning yang sebenarnya? Dan bagaiman Blended Learning kemudian bisa menjadi alternatifnya? berikut pembahasan mengenai e learning serta blended learning dan pembelajarannya secara lebih lanjut.

\section{Memperdalam E-Learning}

Ada banyak istilah atau terminology yang mengacu pada kata e learning, seperti virtual learning, online learning, virtual class, e-training, dan sebagainya. Di samping itu sulit juga mencari definisi yang jelas tentang e-learning. Tetapi, satu hal yang jelas e learning merupakan istilah generic dari pendayagunaan teknologi elektronik untuk pembelajaran. Untuk itu, kata sebutan e learning merupakan payung dari beberapa istilah lain sebagaimana tersebut. ${ }^{6}$ Lanjut kembali, elearning merupakan pendekatan pembelajaran melalui perangkat komputer yang tersambung ke internet, dimana peserta didik berupaya memperoleh bahan belajar yang sesuai dengan kebutuhannya. E-learning merupakan aplikasi internet yang dapat menghubungkan antara pendidik dan peserta didik dalam sebuah ruang belajar online. ${ }^{7}$ Itu berarti istilah e-learning memiliki cakupan yang luas terhadap ragam penerapannya.

Melalui Jurnal Ananda Hadi Ilyas, definisi e-learning menurut para tokoh diantaranya, Kumar C. Koran (2002), mendefinisikan e-learning sebagai sembarang pengajaran dan pembelajaran yang menggunakan rangkaian elektronik (LAN, WAN, atau internet) untuk

\footnotetext{
${ }^{6}$ Dewi salma prawiradilaga, Mozaik Teknologi Pendidikan :E-Learning. Jakarta : prenadamedia group. Hal.34

${ }^{7}$ Silahudin, , Penerapan E Learning Dalam Inovasi Pendidikan,jurnal ilmiah circuit Vol.1 No.1. 2015. 51

27| Jurnal Auladuna
} 


\section{Jamilatun Nafi'ab}

menyampaikan isi pembelajaran, interaksi, atau bimbingan. Sedangkan Dong (dalam Kamarga, 2002) mendefinisikan elearning sebagai kegiatan belajar asynchronous melalui perangkat elektronik komputer yang memperoleh bahan belajar yang sesuai dengan kebutuhannya. Bahkan Onno W. Purbo (2002) menjelaskan bahwa istilah "e" atau singkatan dari elektronik dalam elearning digunakan sebagai istilah untuk segala teknologi yang digunakan untuk mendukung usaha-usaha pengajaran lewat teknologi elektronik internet. Internet, Intranet, satelit, tape audio/video, TV interaktif dan CD-ROM adalah sebagian dari media elektronik yang digunakan Pengajaran boleh disampaikan secara 'synchronously' (pada waktu yang sama) ataupun 'asynchronously' (pada waktu yang berbeda). ${ }^{8}$

Selain ragam e-learning yang yang telah di sebutkan, secara spesifikasi terdapat tipe tipe elearning dalam penerapannya. ${ }^{9}$ Berikut jenis jenis e-learning.

\section{a. Learner-led E-Learning}

Leaner led -Learning merupakan e-learning yang dirancang untuk membuat peserta dapat belajar secara mandiri. 1stilah Learner-led E-Learning dikenal juga dengan istilah self-directed. Ciri khas dan e-learning ini adalah peserta didik dapat mempelajari materi ajar dengan menggunakan komputer dan tanpa melalui jaringan internet atau web. Materi ajar disusun dan dikemas ke dalam CD-ROM atau DVD.

\section{b. Instructor-led E-learning}

Jenis ini menggunakan janngan internet atau intranet atau web dalam proses pembelajaran. oleh sebab itu maka dalam pembelajaran diperlukan teknologi seperti video, audio, chatting, bulletin board dan sejenisnya.

c. Facilitated E-Learning

Peserta didik dapat belajar secara mandiri dengan mengakses materi ajar seperti video, gambar bergerak dalam berbagai format dañ website. Selain itu peserta didik dapat melakukan interaksi seperti komunikasi dan berkolaborasi melalui website. Interaksi tersebut dapat dilakukan melalui konferensi, forum, diskusi chatting, dan Iainnya.

\section{d. Embedded E-Leaming}

Jenis e-Ieaming merupakan alat yang dapat memberikan bantuan kepada peserta didik ketika mengalami kesulitan saat belajar. Bantuan tersebut dapat berupa instruksi, diagram, atau metode yang tersedia untuk membimbing peserta didik. Itulah sebabnya Embedded e-

\footnotetext{
${ }^{8}$ Ananda Hadi Elyas, Jurnal Warta Edisi : 56, Penggunaan Model Pembelajaran E-Learning Dalam Meningkatkan Kualitas Pembelajaran, April 2018, 5

${ }^{9}$ Lidia simanihuruk dkk, 2019. e-learning:implementasi, strategi dan inovasinya.yayasan kita menulis.. hal 15
} 
learning disamakan dengan electronic performances support system (Sistem Pendukung Kinerja Elektronik).

e. Telementoring and e-coaching

Jenis e-Ieaming ini menggunakan jaringan internet dan web dalam melakukan pembelajaran jarak jauh. Untuk membantu peseta didik menguasai pengetahuan, memantau perkembangan keterampilan dan ikap maka digunakan telekonferensi, instant messaging dan chatting.

Kesimpulan yang bisa penulis tanggapi dari berbagai pengertian tersebut bahwa elearning adalah pembelajaran berbasis peralatan maupun perangkat elektronik, baik secara online maupun offline yang bisa di lakukan secara jarak jauh maupun tatap muka guna tercapainya tujuan pembelajaran.

Selanjutnya Muhammad Rusli menyatakan e-learning memiliki fungsi terhadap kegiatan pembelajaran di era normal baru atau selama pandemic Covid 19. Diantara fungsi tersebut yaitu sebagai suplemen (bersifat pilihan/opsional), pelengkap (komplemen), atau pengganti (substitusi). ${ }^{10}$ Berikut ulasan lebih lanjut.

\section{a. Suplemen}

Sebagai suplemen (tambahan), artinya e-learning dapat menjadi alternative bagi guru dalam melakukan menyampaikan materi secara fleksibel dan mudah. Begitu juga dengan peserta didik bias memperoleh wawasan dan informasi tambahan selain yang ia dapat melalui pembelajaran konvensional atau hanya tatap muka saja.

\section{b. Komplemen (Pelengkap)}

Sebagai pelengkap apabila pembelajaran elektronik memang di programkan untuk melengkapi materi yang di terima oleh siswa. Selain itu, fungsi e-learning sebagai pelengkap disini bisa menjadi penguat pemahaman siswa jika pada pembelajaran tatap muka konvensional siswa yang masih memiliki kesulitan belajar, sebagai pengayaan maupun kegiatan remedial bagi pemahman siswa.

\section{c. Pengganti (Substitusi)}

Penerapan e-learning bisa dianggap sebagai pembelajaran yang bisa di gunakan secara jarak jauh dan dapat menyesuaikan waktu dan aktivitas peserta didik.

\footnotetext{
${ }^{10}$ Muhammad rusli dkk, 2020, memahami e-learning:konsep, teknologi dan arah perkembangan, Yogyakarta: CV ANDI OFFSET. Hal. 5
} 


\section{Jamilatun Nafi'ab}

\section{Penerapan E-Learning di Era Normal Baru}

Pembelajaran dengan menggunakan teknologi atau e-learning yang pertama disiapkan adalah konten atau materi pembelajaran yang dapat dikemas dengan menggunakan video, audio atau teks dalam presentasi powerpoint. Materi yang sudah siap maka dilakukan proses pembelajaran dengan menempatkan materi pada website LMS (Learning Management System) secara asinkronus (online tanpa tatap layar) atau melalui video conference secara sinkronus (tatap layar). Outpunya berupa hasil belajar dan evaluasi peserta didik dengan mengerjakan ujian, quiz, tugas dan memberikan umpan balik sebagai evaluasi. ${ }^{11}$ Penerapan e learning seperti ini haruslah di dukung dengan fasilitas elektronik yang mumpuni dan tentunya terhubung lewat internet.

Pengemasan materi yang akan disusun dalam e-learning agar lebih bermakna terhadap pembelajaran peserta didik salah satunya adalah bisa mengaitkan materi pelajaran dengan kehidupan nyata peserta didik sehingga mereka bisa menghubungkan situasi nyata dengan pengetahuan yang di dapatkannya. Hal ini bertujuan agar merangsang motivasi serta rasa keingintahuan peserta didik dalam memperoleh pngetahuan yang di pelajarinya. ${ }^{12}$ Ini berarti penerapan e-learning bisa di kaitkan dengan pembelajaran konstekstual dan bisa $u$ p todate terhadap perkembangan dunia saat ini.

Selanjutnya, bila tujuan, persiapan serta pengemasan materi telah di lakukan, langkah berikutnya adalah pemilihan penyampaian atau cara memberikan materi tersebut agar dapat di terima oleh peserta didik melalui pembelajaran e-learning. Salah satu cara elearning bisa di terapkan melalui berbagai aplikasi yang telah di sediakan melalui media social, diantaranya facebook, twitter, you tube, whatsapp, telegram, tik, tok, dan sejenisnya. Selain itu, elearning bisa di jalankan melalui program yang telah di setting oleh pihak institusi seperti melalui fitur google classroom, google meet, zoom dan sejenisnya. ${ }^{13}$ Pemilihan aplikasi tersebut haruslah memperhatikan situasi dan kondisi masing masing Lembaga Pendidikan dan peserta didik.

\footnotetext{
${ }^{11} \mathrm{Ni}$ Nyoman Supuwaningsih, 2021. E-Learning untuk pembelajaran abad 21dalam menghadapi era revolusi industry 4.0, bandung : CV Media Sains Indonesia, hal 56

${ }^{12}$ UhlulQoriawati,Lu'luil Maknun, Jurnal Edukasi Madrasah Ibtidaiyah, Upaya Peningkatan Kualitas Pembelajaran Daring Bagi Pesrta Didik pada masa Pandemi Covid-19, Vol 3 No.1 Januari 2021, 7

${ }^{13}$ Mohammad Solehudin, Jurnal Mudarrisuna, dampak covid-19: guru mengadopsi media social sebagai elearning pada pembelajaran jarak jauh, Vol 10 No.1 Januari-Maret 2020, 4
} 
Berbagai aplikasi media social tersebut yang sering di gunakan dalam pembelajaran jarak jauh di tingkat Madrasah Ibtidaiyah/ Sekolah Dasar saat pandemic Covid-19 hingga New Normal saat ini diantaranya; Aplikasi WhatsaApp. ${ }^{14}$ Berikut contoh penerapan elearning dengan aplikasi whatsapp messenger.

Pada langkah persiapan pengajaran, guru mempersiapkan materi yang akan dijadikan sebagai bahan ajar. Pada masa pandemic ini, guru tidak hanya membaca materi, tetapi juga harus mempertimbangkan cara yang tepat untuk mentransformasi materi tersebut agar bisa diunggah pada platform online. Beberapa guru kebanyakan menggunakan platform WhatsApp, pemilihan platform ini didasari sebagai media komunikasi berbasis internet yang sering di gunakan. Penyajian materi pada platform WhatsApp disajikan dengan bentuk visual dan audio, yaitu dengan memberikan foto halaman buku ajar, kemudian menjelaskannya secara verbal melalui voice note. ${ }^{15}$

Selain itu, penggunaan aplikasi e learning yang sering digunakan oleh pendidik diantaranya melalui zoom meeting. Aplikasi tersebut bisa di gunakan jika terdapat materi yang perlu di sampaikan secara lisan dan tatap muka secara online. Seperti contoh pada mata pelajaran Pendidikan Jasmani dan Olahraga Kebugaran, (PJOK), Ilmu Pendidikan Alam (IPA) ataupun mata pelajaran dalam Pendidikan Agama Islam (PAI) yang mengandung ,muatan materi praktik dan eksperimen.

\section{Manfaat E-Learning}

E-learning merubah model pembelajaran tradisional menjadi visual dan tanpa tatap muka. Para pengajar dapat menyediakan bahan-bahan pelajaran untuk peserta didik (siswa), mengontrol materi yang diajarkan, rnengeksplorasi kegiatan masing-masing peserta didik seperti kita absensi online, pengumpulan tugas, dan lain-lain. Kadang-kadang, pengajar juga dapat mengatur chat online dengan peserta, mengumumkan beberapa informasi, dan memberikan masukan berharga bagi siswanya. ${ }^{16}$ ini berarti adanya pembelajaran e-learning bisa memberikan ruang gerak secara bebas namun tetap terprogram baik bagi pendidik maupun peserta didik.

\footnotetext{
${ }^{14}$ Andika Prajana, Jurnal Pendidikan Teknologi Informasi, Pemanfaatan Aplikasi Whatsapp Dalam Media Pembelajaran Di Uin Ar-Raniry Banda Aceh, Volume 1, Nomor 2, Oktober 2017, 3

15 16. Tubagus penambaian, Penerapan Program Pengajaran Dengan Model Blended Learning Pada Sekolah Dasar Di Kota Rantau, Jurnal Analytica Islamica, Vol.22 No.1 januari - juni 2020. 6

${ }^{16}$ Suharyanto, Adel, Penerapan E- Learning Sebagai Alat Bantu Mengajar Dalam Dunia Pendidikan, jurnal ilmiah widya, vol 2 no.4 Agustus-September.2016. 19
} 
Selain manfaat tersebut, ada lagi beberapa manfaat yang bisa dinikmati dari proses pembelajaran dengan e-learning, diataranya :

a. Fleksibilitas.

Jika pembelajaran konvensional di kelas mengharuskan siswa untuk hadir di kelas pada jam-jam tertentu (seringkali jam ini bentrok dengan kegiatan rutin siswa), maka elearning memberikan fleksibilitas dalam memilih waktu dan tempat untuk mengakses pelajaran. Siswa tidak perlu mengadakan perjalanan menuju tempat pelajaran disampaikan, e-learning bisa diakses dari mana saja yang memiliki akses ke Internet. Bahkan, dengan berkembangnya mobile technology semakin mudah mengakses e-learning. Berbagai tempat juga sudah menyediakan sambungan internet gratis (di bandara internasional dan cafe-cafe tertentu), dengan demikian dalam perjalanan pun atau pada waktu istirahat makan siang sambil menunggu hidangan disajikan, Anda bisa memanfaatkan waktu untuk mengakses elearning

b. Independent Learning

E-learning memberikan kesempatan bagi pembelajar untuk memegang kendali atas kesuksesan belajar masing-masing, artinya pembelajar diberi kebebasan untuk menentukan kapan akan mulai, kapan akan menyelesaikan, dan bagian mana dalam satu modul yang ingin dipelajarinya terlebih dulu. ${ }^{17}$

\section{Blended Learning dan Penerapannya di Era Normal Baru}

Blended learning merupakan kombinasi karakteristik pembelajaran tradisional dan lingkungan pembelajaran elektronik. Artinya pembelajaran blended learning menggabungkan aspek blended learning (format elektronik) dengan pembelajaran tradisional "tatap muka". ${ }^{18}$ Hadion Wijoyo dalam bukunya yang juga mengulas panduan blended learning menyatakan bahwa adanya blended learning merupakan sebuah kemudahan pembelajaran yang menggabungkan berbagai cara penyampaian, model pengajaran, dan gaya pembelajaran, memperkenalkan berbagai pilihan media dialog antara fasilitator dengan orang yang mendapat pengajaran. Blended learning juga sebagai sebuah

\footnotetext{
${ }^{17}$ Ananda Hadi Elyas, Jurnal Warta Edisi : 56, Penggunaan Model Pembelajaran E-Learning Dalam Meningkatkan Kualitas Pembelajaran, April 2018, 5

${ }^{18}$ Utami Novita Lestari, Rohana Sufia, Journal Of Islamic Education at Elementary School. Implementasi Blended Learning Selama Masa Pandemi Covid-19 Untuk Menumbuhkan Kemandirian Siswa Pada Mata Pelajaran Matematika di SD YP Nasional Surabaya. Vol 1. No.2, Desember 2020, 3
} 
kombinasi pengajaran langsung (face-to-face) dan pengajaran online, tapi lebih dari pada itu sebagai elemen dari interaksi sosial. ${ }^{19}$

Pengertian tersebut sama-sama menyatakan bahwa blended learning adalah pembelajaran yang menggabungkan dan mengkombinasikan antara e-learning dengan pembelajaran tatap muka. Itu berarti, adanya blended learning komunikasi tidak hanya tertahan lewat elektronik saja tetapi juga bisa terjadi interaksi secara langsung.

Blended learning atau bisa kita bahasakan pembelajaran campuran ini memiliki daya Tarik tersendiri dalam penerapannya. Hal ini di utarakan oleh Kaye Thorne dalam bukunya "Blended Learning How To Integrate Online \& Traditional Learning". Berikut kutipannya:

"Blended learning is the most logical and natural evolution of our learning agenda. It suggests an elegant solution to the challenges of tailoring learning and development to the needs of individuals. It represents an opportunity to integrate the innovative and technological advances offered by online learning with the interaction and participation offered in the best of traditional learning. It can be supported and enhanced by using the wisdom and one-to-one contact of personal coaches." 20

Artinya blended learning ini pembelajaran yang elegan tidak kaku dan bisa menyesuaikan kebutuhan pembelajar. Pemahaman yang kurang jelas lewat e learning bisa di perjelas melalui tatap muka dan begitupun sebaliknya. Hal ini di perjelas Kembali salah satu poin penting blended learning turut di terapkan menurut pernyataan Curtis J.Bonk dan Charles R. Graham ialah;

"Blended learning, should be sure to consolidate their understanding of its manifestation in the distance education context. Certainly one can, and should, study the concept from the point of view of the classroom teacher and the pedagogical theories underlying classroom practice. However, blending face-toface teaching with those forms of teaching in which the principal delivery technology is not the classroom, but is a mechanical or electronic technology, that is, distance education, is so important that blended learning will not be fully understood if one's perspective is only that of the classroom teacher and does not include knowledge of research and practice in the distance education field."21

Blended learning bisa efektif di terapkan pada peserta didik di tingkat Madrasah Ibtidaiyah/ sekolah dasar. Melihat, peserta didik di tingkat MI/SD Sebagian kelas masih

\footnotetext{
${ }^{19}$ Hadion Wijoyo dkk, Blended Learning Suatu Panduan Sumatra Barat: Insan Cendekia Mandiri, 2020,2

${ }^{20}$ Kayethorne, , Blended Learning how to integrate online \& traditional learning, London: kogan page. 2003, hal. 2

${ }^{21}$ Curtis J.Bonk, Charles R. Graham, The Handbook Of Blended Learning, San Francisco : Pfeiffer. 2006, hal.25
} 


\section{Jamilatun Nafi'ab}

berada pada kognitif tahap operasional konkret, sehingga konsep materi yang masih bersifat abstrak bisa di jelaskan secara nyata melalui kombinasi blended learning tersebut.

Blended Learning merupakan proses pembelajaran yang memanfaatkan berbagai macam pendekatan. Pendekatan yang dilakukan dapat memanfaatkan berbagai macam media dan teknologi. Pembelajaran berlangsung secara konvensional (tatap muka), mandiri, dan mandiri via online. Bahan belajar mandiri secara offline disiapkan dalam bentuk digital, seperti dalam bentuk CD, MP3, DVD, dll, sedangkan bahan belajar mandiri secara online disiapkan dalam bentuk Mailing List, Social Media, Learning Management Systems (LMS)dan lain sebagainya.

Penerapan Blended Learning pendidik seharusnya dapat memastikan bahwa seluruh pesertanya memiliki sarana dan prasarana yang memadai, sehingga dalam belajar secara mandiri via online tidak banyak hambatan dikarenakan faktor sarana dan prasana yang kurang memadai. Selain itu pendidik sudah menyiapkan solusi terbaik dalam mengatasi permasalahan yang mungkin muncul.Pembagian materi belajar harus dapat dialokasikan dengan baik, dengan mempertimbangkan isi bahan ajar, serta tujuan pembelajarannya, mana yang harus dibahas secara tatap muka, atau dapat dipelajari secara mandiri. Dalam mengorganisir pembelajaran, pendidik juga harus menyiapkan jadwal yang terorganisir untuk tatap muka dan pembelajaran mandiri diawal, agar peserta mengetahuisecara jelas jadwal tersebut. ${ }^{22}$

Manfaat pembelajaran blended learning Sebagian memiliki persamaan denga napa yang ada dalam e-learning karna Sebagian dari proses blended learning merupakan penerapan dari e-learning atau pembelajaran melalui elektronik. Namun, adanya blended learning disini pembelajaran tidak hanya menarik karna adanya media elektronik namun adanya tatap muka dalam blended learning tersebut bisa menciptakan interaksi secara langsung dan penjelasan bisa tersampaikan secara jelas.

\section{KESIMPULAN}

Pembelajaran e-learning adalah pembelajaran yang menggunakan media eletronik dalam penerapannya. Sedangkan blended learning merupakan perpaduan antara pembelajaran konvensional dan digital. Baik e-learning maupun blended learning sama sama memiliki keunggulan

\footnotetext{
${ }^{22}$ Blog: Wendhie Prayitno, Widyaiswara, Implementasi Blended Learningdalam Pembelajaran Pada Pendidikan Dasar Dan Menengah, (di posting: 24 Feb 2015) (http://lpmpjogja.kemdikbud.go.id/wpcontent/uploads/2015/02/Blended- Learning_Wendhie.pdf (di akses 23 Maret 2021)
} 
dan manfaat tersendiri. Pada awal pandemi Covid 19, Penerapan kedua pembelajaran tersebut memang menjadi alternatif agar pembelajaran tetap berlangsung dan terlaksana. Namun, selain hanya tertuju pada bentuk pembelajaran, di harapkan pendidik perlu memperhatikan beberapa hal seperti fasilitas belajar, sarana prasaran, termasuk kondisi yang sesuai dengan kebutuhan peserta didik. Hal tersebut bertujuan agar dalam pelaksanaanya berbagai permasalahan dapat teratasi. Inilah inti dari Penyesuaian atau adaptasi adanya pembelajaran e-learning dan blended learning di era new normal.

\section{REFERENSI}

1. Ananda Hadi Elyas, 2018. Jurnal Warta Edisi : 56, Penggunaan Model Pembelajaran ELearning Dalam Meningkatkean Kualitas Pembelajaran, (diakses 14 Maret 2021)

2. Andika Prajana, 2017. Jurnal Pendidikan Teknologi Informasi, Pemanfaatan Aplikasi Whatsapp Dalam Media Pembelajaran Di Uin Ar-Raniry Banda Aceh, Vol 1 No. 2 (diakses 14 Maret 2021)

3. Curtis J.Bonk, Charles R. Graham, 2006. The Handbook Of Blended Learning, San Francisco : Pfeiffer.

4. Dewi salma prawiradilaga, 2013. mozaik teknologi pendidikan :E-Learning. Jakarta : prenadamedia group.

5. Departemen Agama RI. Al-Qur'an dan Terjemahannya, 2006. Surabaya: CV.Pustaka Agung Harapan

6. Hadion Wijoyo dkk, 2020. Blended Learning Suatu Panduan Sumatra Barat: Insan Cendekia Mandiri,

7. HS Wibowo 2014. Indonesian Journal of History Education, Efektivitas Pembelajaran Sejarah Dengan Mengunakan Model Pembelajaran E -Learning Vol.3 No.1 17 Oktober (di akses 20 Maret 2020)

8. Kayethorne, 2003. Blended Learning How To Integrate Online \& Traditional Learning, London: kogan page,

9. Lidia simanihuruk dkk, 2019. E-Learning:Implementasi, Strategi Dan Inovasinya. yayasan kita menulis.

10. Muhammad rusli dkk, 2020. Memahami E-Learning:Konsep, Teknologi dan Arah Perkembangan, Yogyakarta: CV ANDI OFFSET. 


\section{Jamilatun Nafi'ab}

11. Mohammad Solehudin, 2020. Jurnal Mudarrisuna, dampak covid-19: Guru Mengadopsi Media Social Sebagai E-Learning Pada Pembelajaran Jarak Jauh, Vol 10 No.1 Januari-Maret, (di akses 20 Maret 2020)

12. Ni Nyoman Supuwaningsih, 2021. E-Learning untuk pembelajaran abad 21 dalam menghadapi era revolusi industry 4.0, bandung: CV Media Sains Indonesia.

13. Silahudin. 2015. Penerapan E Learning Dalam Inovasi Pendidikan,jurnal ilmiah circuit Vol.1 No.1. (di akses 20 Maret 2020)

14. Suharyanto, Adel, 2016. Penerapan E- Learning Sebagai Alat Bantu Mengajar Dalam Dunia Pendidikan, Jurnal Ilmiah Widya, vol 2 no.4 Agustus-September. (di akses 20 Maret 2020)

15. Uhlul Qoriawati,Lu’luil Maknun, 2021. Jurnal Edukasi Madrasah Ibtidaiyah, Upaya Peningkatan Kualitas Pembelajaran Daring Bagi Pesrta Didik pada masa Pandemi Covid19, Vol 3 No.1 Januari, (di akses 23 Maret 2021).

16. Utami Novita Lestari, Rohana Sufia, 2020. Journal Of Islamic Education at Elementary School. Implementasi Blended Learning Selama Masa Pandemi Covid-19 Untuk Menumbubkan Kemandirian Siswa Pada Mata Pelajaran Matematika di SD YP Nasional Surabaya. Vol 1. No.2, Desember. (di akses 23 Maret 2021).

17. Tubagus penambaian, 2020. Jurnal Analytica Islamica . Penerapan Program Pengajaran Dengan Model Blended Learning Pada Sekolah Dasar Di Kota Rantau, , Vol.22 No.1 januari juni. (di akses 23 Maret 2021).

18. Wendhie Prayitno, Widyaiswara, Implementasi Blended Learningdalam Pembelajaran Pada Pendidikan Dasar Dan Menengah, (di posting: 24 Feb 2015) (http://lpmpjogja.kemdikbud.go.id/wp-content/uploads/2015/02/BlendedLearning Wendhie.pdf (di akses 23 Maret 2021). 